\title{
Expanding the Lexicon: The Case of Jordanian Arabic
}

\author{
Zainab Sa'aida \\ Department of English, Tafila Technical University, Jordan \\ E-mail: saaidazainab@yahoo.com
}

Doi:10.7575/aiac.alls.v.7n.6p.9

Received: 07/07/2016

URL: http://dx.doi.org/10.7575/aiac.alls.v.7n.6p.9

Accepted: 14/09/2016

\begin{abstract}
The aim of this study is to explore (non)morphological processes that native speakers of Jordanian Urban Arabic and Jordanian Rural Arabic use to expand their own lexicon. Three Jordanian female respondents were interviewed to collect data. The data consist of transcriptions of recorded tokens, which were categorised into groups according to the (non)morphological processes that they undergo. Findings of the study show that there is a number of (non)morphological processes that native speakers of Jordanian Urban Arabic and Jordanian Rural Arabic use to enlarge their own lexicon. The morphological processes include affixation, suppletion, conversion, and vowel mark placement. The present study has also explored a number of non-morphological processes which include univerbation, borrowing, and word creation.
\end{abstract}

Keywords: Lexicon, Jordanian Arabic, (non)morphological processes, (non)concatenative, word-formation

\section{Introduction}

No natural language would be imagined to live without having word-formation processes; they alter stems to derive new words in the language. We need new words, as language users need new expressions to refer to new objects or concepts (Booij, 2005). One of the means for expanding the lexicon of a language is word-formation processes. The study of word-formation is defined as "the study of the ways in which new complex words are built on the basis of other words or morphemes" (Plag, 2003: p. 13). Languages have two different kinds of morphological relationships among words: derivational where word-formation processes may change the word's meaning or part of speech and inflectional where the processes change the word's grammatical function. There are various types of word-formation processes. Some of these processes are concatenative, i.e. "the combination of elements into a linear sequence" (Booij, 2005: p. 9; cf. Haspelmath and Sims (2010)). Affixation is an example of a concatenative process, as in the English word happiness where the morpheme -ness is added to the stem happy. Another example is reduplication in which a word is copied completely or partially and added to that base word, as in Papua Malay words ada 'sibling' < ada-ada 'siblings' (total reduplication) and anak 'child' < an-anak 'children' (partial reduplication) (Booij, 2016). Other processes are called non-concatenative processes where they alter the internal properties of morphemes or a word's internal structure - for example, new words might be made by the replacing of vowels as in sing > sang (Booij, 2005). The use of a tone pattern as a morphological marker in tonal languages is another example of a non-concatenative process (Booij, 2016). Examples of tone patterns are the Ngiti, a central Sudanic language of Congo, singular form màlimò 'teacher' and the plural form màlímó 'teachers' where the Mid-Low tones of the penultimate and ultimate syllables are replaced by High tones in the plural form (Kutsch Lojenga, 1994).

The set of lexical items and complex words in a language can also be enlarged by other non-morphological processes. Lexical borrowing is one of non-morphological processes (see Sa'id, 1967; Suleiman, 1985; Sa'aida, 2015). For example, in Booij (2005) Dutch borrowed the English words deduce, induce, and reduce as deduceer, induceer, and reduceer, respectively. Those borrowed words are created by a non-morphological process rather than morphological, since there is no lexeme DUC in Dutch or in English that those words could have been derived from. Univerbation is another source of complex words in a language; the words might be nouns or adjectives. Examples from English are forget-me-not (noun) and over-the-top (adjective). Other non-morphological sources for new words in a language are blends, acronyms, clippings, and truncations. Modern Standard Arabic has a few blends such as kahrutiisi $<$ kahruba? + mayna:țisi 'electricity + magnetic' and PafruPa:sjawi < Pafri:qi + Pa:sjawi 'African + Asian'. In English the word brunch is a blend of breakfast and lunch. Examples of Saudi Arabic acronyms are <rs> rija:l suGu:di 'Saudi riyal' and <was> waka:lat ?al?anba:? ?assuSu:dijjah 'Saudi Press Agency' (Al-Jarf, 2011). English has a large number of acronyms; some of those are TESL < Teaching English as a second language>, TEFL <Teaching English as a foreign language>, IELTS <International English language testing system>, TOEFL <Test of English as a foreign language>, and NATO < North Atlantic Treaty Organization>. An example of clipping in German is the word uni <universität> 'university', in French is the word labo <laboratoire> 'laboratory', in English is the word flu <influenza>, and in Spanish is the word foto <fotografia > 'photograph'. However, clippings are not attested in Arabic (cf. Al-Jarf, 2011). As for truncation, many European languages seem to have it. For example, English has the truncated names Jenny $<$ Jennifer>, Liz <Elizabeth>, and Will <William>. Some of the truncated names in Dutch are Hans <Johannes>, Henk $<$ Hendrik>, and Sanne <Suzanne> (Booij, 2005). 
There has been no much attention paid to the (non)morphological processes that Jordanian Arabic (JA, henceforth) undergoes to extend its own lexicon. Linguists (e.g. Al-Wer, 2007) focused on the morphology of number, gender, and pronouns in Jordanian Urban Arabic of Amman, the capital city of Jordan. Other linguists' (e.g. Sa'id, 1967; Suleiman, 1985; Sa'aida, 2015) work presented accounts of lexical borrowing in JA. As far as I know, the literature lacks any study that covers morphological and non-morphological processes that Jordanian Urban Arabic (JUA, henceforth) and Jordanian Rural Arabic (JRA, henceforth) undergo. This study is the first in its scope to explore morphological and nonmorphological processes that two Jordanian dialectal varieties, JUA/JRA, undergo to expand their own lexicon. Findings of the study will add more to the literature of Jordanian Arabic morphology. They will be of great interest to morphologists who are unfamiliar with Jordanian Arabic and who investigate cross-linguistic, morphological issues. This article is organised as follows. The first section provides a brief introduction to the topic of this article and presents the rationale behind this study. The next section provides the reader with a background on the linguistic situation in Jordan. Section 3 presents data collection techniques. Section 4 presents results of the study and provides a discussion of the results. I sum up in section 5.

\section{The linguistic situation in Jordan}

The official language in Jordan is Jordanian Arabic; it is used mostly in all social settings in Jordan. There are three main varieties of JA: JUA, JRA, and Jordanian Bedouin Arabic (JBA). Each of these dialects has its own phonological system and phonemic inventory (For the phonological system and phonemic inventory of JUA, see Sa'aida (2015) and for the phonemic inventories of JRA and JBA, see Al Tamimi (2001)). Each of which has also its own lexical stock although lexical items which originated in Modern Standard Arabic (MSA) are shared. For example, the MSA word /'laban/ 'yoghurt' is realised as ['laban] in JUA and JRA, and as ['liban] in JBA. The MSA word /ba' Cirr/ 'camel' is realised as ['zamal] in JUA, ['dzamal] or [ba' 'iirr] in JRA, and as [bi' 'iir] in JBA. Classical Arabic is used in religious settings, specifically when reading in the Holy books of Quran or the Bible. MSA is considered the second language in Jordan in which Jordanian speakers acquire at an early age when they go to kindergarten or school. It is mainly used in rather formal settings such as political speeches, news, newspaper articles and all other written contracts and transactions.

Turkish loanwords entered JA during the Ottoman Empire. Most of those loanwords were in the fields of military, administration, professions, and clothes. Some of those loanwords have been used exclusively in rural areas. However, most of them have been now replaced by JUA words or by English loanwords in urban cities. For example, the English loanword /ko:t/ 'coat' substituted the Turkish loanword/'ba:lț/ 'coat', and the Jordanian word /fur'sa:n/ 'cavalry' replaced the Turkish loanword /șa'wa:ri/ 'cavalry'. By the arrival of the British mandate in 1921 English started to be used constantly in different settings. Compulsory English courses started to be taught in Jordanian schools and universities. Over recent decades, American English has made its way into JA through the introduction of the Internet; particularly through the introduction of social networking. TV news started to be casted in both Arabic and English. A large number of English loanwords entered JA in different semantic fields of cosmetics, technology, transportation, sport, food, and clothes.

\section{Data collection}

The data of the study consist of transcriptions of recorded tokens (i.e. JUA/JRA words and foreign loanwords). The data were gathered from three female native speakers of JA; two of them speak JRA and one respondent speaks JUA. The data were recorded using a compact high-fidelity digital recorder. Consent for taking part in the study and for recording answers was sought from the respondents. The respondents were asked to answer either direct or indirect questions about Jordanian words or foreign loanwords that they use in a few interviewed sessions. The data were transcribed using the IPA (International Phonetic Alphabet) symbols (see appendix A). Phonemic transcriptions of the tokens were provided and glosses were provided, as well, when necessary. The data were classified into groups according to the morphological or non-morphological processes that they undergo.

\section{Results and Discussion}

This section presents the results of the current study and provides the reader with a discussion of the results according to the morphological or non-morphological processes.

\subsection{Morphological processes}

Word-formation processes are divided into two types: concatenative and non-concatenative. The following two subsections discuss these two types.

\subsubsection{Concatenative Processes}

Concatenative processes are morphological processes consist of adding a morpheme to a stem. The following paragraphs discuss types of concatenative processes in JA.

\subsubsection{Affixation}

JA has its own rules of forming words. In affixation a morpheme is attached to a root. JA has only one type of affixes, i.e. bound morphemes - affixes that are attached to the end of a root, i.e. suffixes. The list in (1) presents some JA (applicable to JUA and JRA) suffixed words. 
/a/, kasrah ; a similar diagonal line placed below a letter and represents the short vowel /i/, and dammah $;$; a small curl-like diacritic placed above a letter and represents the short vowel /u/. Vowel marks serve to make distinctions between the JUA /JRA words in (4) and their syntactic categories.

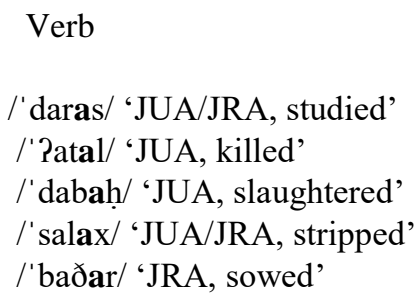

The vowel mark fathah , bold /a/, in the examples above and the vowel mark kasrah 9 , bold /i/, are used to distinguish between verbs and nouns or gerunds, respectively. For example, the JUA/JRA word 'daras 'studied' is a verb of a past tense, which is distinguished by the vowel mark /a/ from the word 'daris 'lesson', being marked with /i/, which serves as a noun. The vowel marks in JA are also used to mark different meanings, as the examples from JUA/JRA in (5) show.
/'Sa:lim/ 'scientist'
/' 'a:lam/ 'world'
/dgidd/ 'grandfather'
/dgadd/ 'seriousness'
/'sihir/ 'magic'
/'Gilim/ 'knowledge'
/'sahar/ 'dawn'
/'Salam/ 'flag'

The examples in the list above show that the use of different vowel marks, bold /i/ and /a/, results in words, which share the same set of consonants and/or long vowels, with different meanings. For example, the adding of the vowel marks /i/ or /a/ to the root $\zeta l m$ result in two words with two different meanings: 'Silim 'knowledge' and 'Salam 'flag'.

\subsection{Non-morphological processes}

Apart from morphological processes, there are three non-morphological processes that play an important role in the expanding of the lexicon in JA: univerbation, borrowing, and word creation or word manufacturing.

\subsubsection{Univerbation}

The first source of complex words in JA is the univerbation of phrases. Booij (2005) defines univerbation as the lexicalisation of phrases into words; the process which leads to complex words. The words in (6) below illustrate univerbation of JA phrases into complex words.

(6) / / $\mathrm{u} \iint-\mathrm{ilbulbul} / \mathrm{JUA} / \mathrm{JRA}$, literally nest the nightingale, a type of Middle Eastern sweet made of vermicelli, pistachio, and syrup that looks like a bird's nest'

/timm-issamaki/ 'JUA, literally mouth the fish, a small garden plant with white, pink, purple, and burgundy flowers that looks like a fish's mouth'

/lsa:n-ilGuṣfu:r/ 'JUA/JRA, literally tongue the sparrow, meat from lamb that is cut into small rectangle-shaped pieces'

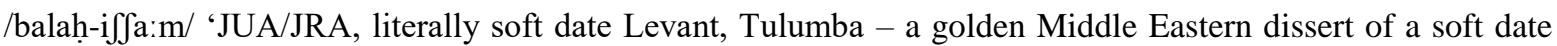
size'

/luPmit-ilPa:dii/ 'JUA, literally a bite the judge, a circle-shaped Middle Eastern dissert that has a glazed surface'

/Pum-kalӨo:m/ 'JRA, literally mother Kalthome - a female name, a small garden plant with pink, white, and yellow flowers that grows from seed every year'

/Pilmann-wis-salwa/ 'JUA/JRA, literally hardened honey and quail, a type of Middle Eastern dissert that is made from a sticky raw honey, being collected from trees, flour and nuts'

All the examples above are categorised as nouns in JA. In the first example, Suff-ilbulbul consists of two constituents which are clearly recognisable, and their meanings are relevant. The words $\subseteq u f \int$ 'nest' and ilbulbul 'the nightingale' are 
words in JUA and JRA. Therefore, Guff-ilbulbul is a complex, bimorphemic word. However, this does not imply that this complex word has been created by a morphological rule. The last example, Pilmann-wis-salwa, consists of three constituents which can be easily recognised by native speakers of JA; however, their meanings are irrelevant. This infers that it is not necessary for complex words in JUA/JRA which are created by the process of univerbation to consist of words which are semantically relevant.

\subsubsection{Borrowing}

Lexical borrowing is a term that "involves the incorporation of individual L2 words (or compounds functioning as single words) into discourse of L1, the host or recipient language, usually phonologically and morphologically adapted to conform with the patterns of that language, and occupying a sentence slot dictated by its syntax" (Poplack et al., 1988: 52). JA has borrowed many words from English, Turkish, Hindi (through other Arabic dialects), French and Italian (through Egyptian Arabic). The following list provides examples of Ottoman Turkish borrowed words into JRA.

$$
\begin{aligned}
& \text { /' gahwadzi/ 'coffee shop waiter' } \\
& \text { /'ṣofradzi/ 'waiter' } \\
& \text { /'makwadzi/ 'clothes presser' } \\
& \text { /kun' dardzi/ 'shoe maker' } \\
& \text { /'go:ldzi/ 'goal keeper' }
\end{aligned}
$$

The first example, 'gahwadzi, can be analysed into three parts: gah-wa-dzi constituting a polymorphemic word. The constituent -dzi is the recurrent part of all the examples in the list above. The constituents gahwa-, sofra-, makwa-, kundar(a)-, and go:l- are also recognisable elements in the set of words above. However, one cannot say that these words have been created morphologically. This is due to the fact that there is no lexeme -dzi from which these words could have been derived. Instead, these words are borrowed from Ottoman Turkish maintaining the source forms.

\subsubsection{Word creation or word manufacturing}

New words can also be made by means of word creation or word manufacturing. The following types are found in JUA/JRA.

\subsubsection{Acronyms}

Acronym is a word formed from initial letters of a word sequence. The list in (8) shows examples of acronyms in JUA/JRA, where angle brackets indicate spelling.

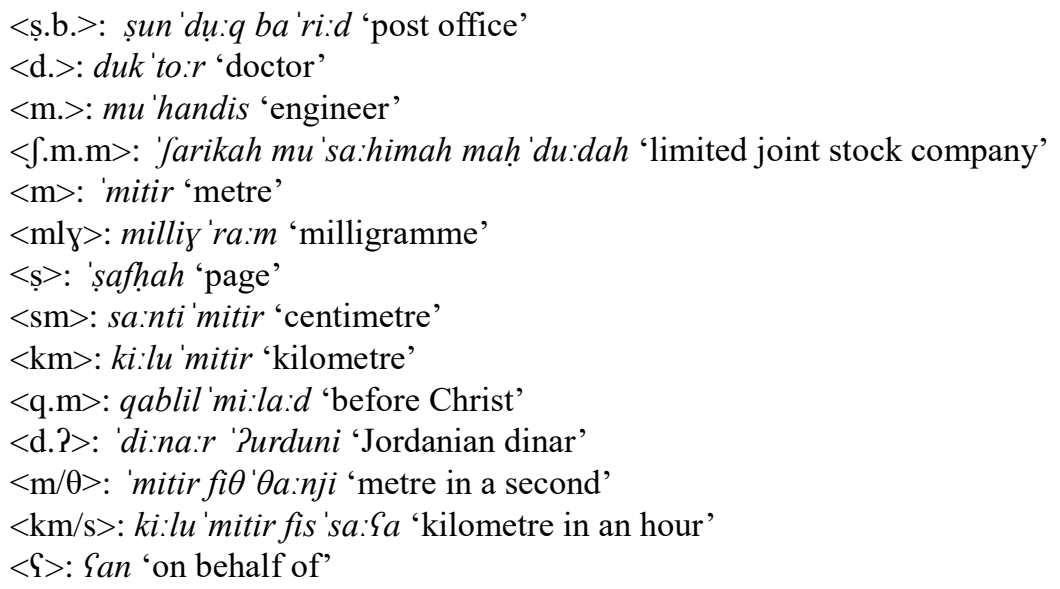

As the list above shows, some acronyms in JA take full points such as $<$ ș.b. $>$ and $<$ d. $>$ whereas some other acronyms do not take full points such as $\langle\mathrm{km}\rangle$ and $\langle\mathrm{sm}\rangle$.

\subsubsection{Truncation}

Truncation is subtracting of one or more syllables of a personal name. In many cases, the core of the truncated name is the stressed syllable of the full form of the name; mostly the truncated name consists of two or three syllables. The following list shows examples of truncated names in JUA/JRA, where the first column presents truncated names, the second column presents full names, and the third column presents glosses.

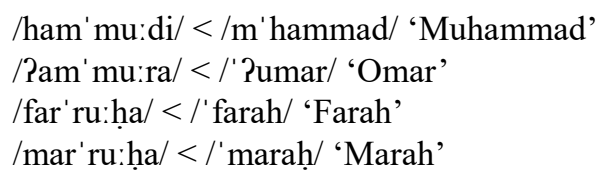

Mostly, in names which begin with sounds like /s/, /l/, /d/, /t/, /z/, / $/$, truncation operates by adding the long vowel /u:/ to the initial sound of the full form and doubling the sequence of the initial sound $+/ \mathrm{u}: /$, as is showed in the list in (10) below. 


(10) /'du:du:/ < /'di:na/ 'Dina',/'di:ma/ 'Dima',/'da:na/ 'Dana'
/'su:su:/ </si'ri:n/ 'Sirin', /sa' ma:h// 'Samah', /su' ha:d/ 'Suhad'
/'lu:lu:/ < /'la:na/ 'Lana', /li:n/ 'Leanne', /lu' dzajn/ 'Lujayn'

\section{Conclusion}

A number of morphological and non-morphological processes that JUA/JRA speakers use to expand their own lexicon have been explored in the present study. The morphological processes have two types: concatenative and nonconcatenative. The concatenative processes include affixation and suppletion while the non-concatenative ones consist of conversion and vowel mark placement. Apart from morphological processes, the present study has explored other non-morphological processes that JUA and JRA undergo to enlarge their sets of simplex and complex words. Those processes include univerbation, borrowing, and word creation. A new word may be created by means of acronyms or truncation. The processes that were used to expand the lexicon of JUA and JRA were the main focus of the current study. Further study needs to be conducted to explore the way that speakers of JBA (i.e. semi-nomads) expand their lexicon.

\section{References}

Al-Jarf, R. (2011). Teaching English word-formation processes to translation students. Komunikacija i kultura, 26, 160174.

Al-Tamimi, F. (2001). Phonetic and phonological variation in the speech of rural migrants in a Jordanian city (Unpublished PhD thesis). University of Leeds, UK.

Al-Wer, E. (2007). Jordanian Arabic. In K. Versteegh, M. Eid, A. Elgibali, M. Woidich \& A. Zaborsky (Eds.), Encyclopedia of Arabic language and linguistics II (pp. 505-517). Leiden, Boston: Brill.

Booij, G. (2005). The Grammar of Words: An Introduction to Linguistic Morphology. Oxford: Oxford University Press.

Booij, G. (2016). Morphology: The structure of words. In K. Allan (Ed.), The Routledge handbook of linguistics (pp. 104-117). London \& New York: Routledge.

Haspelmath, M. \& Sims, A. D. (2010). Understanding Morphology. London: Hodder Education.

Kutsch Lojenga, C. (1994). Ngiti, A Central-Sudanic language of Zaire. Köln: Rüdiger Köppe Verlag.

Plag, I. (2003). Word-Formation in English. Cambridge: Cambridge University Press.

Poplack, S., Sankoff, D., \& Miller, C. (1988). The social correlates and linguistic processes of lexical borrowing and assimilation. Linguistics, 26, 47-104.

Sa'aida, Z. (2015). Aspects of the phonology of English loanwords in Jordanian Urban Arabic: A distinctive feature, moraic, and metrical stress analysis (Unpublished $\mathrm{PhD}$ thesis). University of Leeds, UK.

Sa'id, M. (1967). Lexical Innovation through Borrowing in Modern Standard Arabic. Princeton: Princeton University Press.

Suleiman, S. (1985). Jordanian Arabic between Diglossia and Bilingualism: Linguistic Analysis. Amsterdam; Philadelphia: John Benjamins Publishing Company.

\section{Appendix A}

\section{List of JUA/JRA Phonemic symbols}

1. $/ \mathrm{t} / \mathrm{:}$ voiceless plain dental plosive.

2. /ț/: voiceless emphatic dental plosive.

3. $\mid \mathfrak{t} /$ : voiceless post-alveolar affricate (JRA only).

4. $/ \mathrm{k} /$ : voiceless velar plosive.

5. /q/: voiceless uvular plosive.

6. /P/: voiceless glottal plosive.

7. $/ \mathrm{b} /$ : voiced bilabial plosive.

8. /d/: voiced plain dental plosive.

9. /ḍ/: voiced emphatic dental plosive.

10. /ds/: voiced post-alveolar affricate.

11. /g/: voiced velar plosive (JRA only).

12. /f/: voiceless labiodental fricative.

13. $/ \theta /$ : voiceless interdental fricative (JRA only).

14. /ð/: voiced interdental fricative (JRA only).

15. /ọ/: voiced emphatic interdental fricative (JRA only).

16. $/ \mathrm{s} /$ : voiceless plain alveolar fricative.

17. /ș/: voiceless emphatic alveolar fricative.

18. $/ \mathrm{J} /$ : voiceless post-alveolar fricative.

19. $/ \mathrm{X} /$ : voiceless velar fricative.

20. $/ \mathrm{h} /:$ voiceless pharyngeal fricative.

21. $/ \mathrm{h} /$ : voiceless glottal fricative.

22. /z/: voiced plain alveolar fricative.

23. $|z|$ : voiced emphatic alveolar fricative (JUA only). 